\title{
Damage Mechanisms Of Filled Siloxanes For Predictive Multiscale Modeling Of Aging Behavior
}

\author{
B. Balazs, R. Maxwell, S. deTeresa, L. Dinh, R. Gee
}

This article was submitted to

Materials Research Society National Meeting, San Francisco, CA., April 1-5, 2002

U.S. Department of Energy

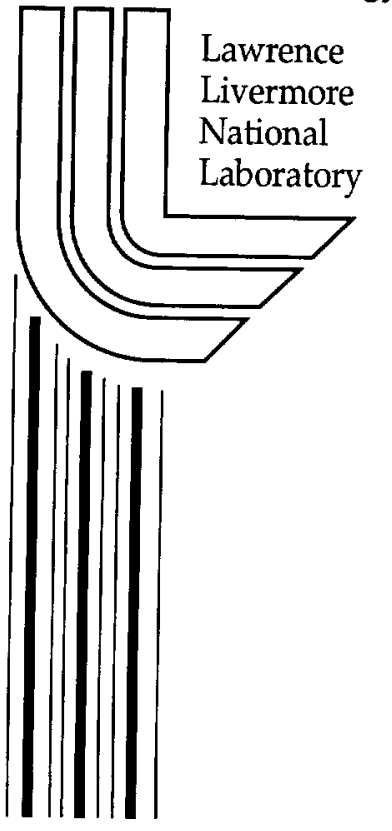

April 2, 2002 


\section{DISCLAIMER}

This document was prepared as an account of work sponsored by an agency of the United States Government. Neither the United States Government nor the University of California nor any of their employees, makes any warranty, express or implied, or assumes any legal liability or responsibility for the accuracy, completeness, or usefulness of any information, apparatus, product, or process disclosed, or represents that its use would not infringe privately owned rights. Reference herein to any specific commercial product, process, or service by trade name, trademark, manufacturer, or otherwise, does not necessarily constitute or imply its endorsement, recommendation, or favoring by the United States Government or the University of California. The views and opinions of authors expressed herein do not necessarily state or reflect those of the United States Government or the University of California, and shall not be used for advertising or product endorsement purposes.

This is a preprint of a paper intended for publication in a journal or proceedings. Since changes may be made before publication, this preprint is made available with the understanding that it will not be cited or reproduced without the permission of the author.

This work was performed under the auspices of the United States Department of Energy by the University of California, Lawrence Livermore National Laboratory under contract No. W-7405-Eng-48.

This report has been reproduced directly from the best available copy.

Available electronically at http://www.doc.gov/bridge

Available for a processing fee to U.S. Department of Energy

And its contractors in paper from

U.S. Department of Energy

Office of Scientific and Technical Information

$$
\text { P.O. Box } 62
$$

Oak Ridge, TN 37831-0062

Telephone: (865) 576-8401

Facsimile: (865) 576-5728

E-mail: reports@adonis.osti.gov

Available for the sale to the public from

U.S. Department of Commerce

National Technical Information Service

5285 Port Royal Road

Springfield, VA 22161

Telephone: (800) 553-6847

Facsimile: (703) 605-6900

E-mail: orders@ntis.fedworld.gov

Online ordering: http://www.ntis.gov/ordering.htm

\section{OR}

Lawrence Livermore National Laboratory

Technical Information Department's Digital Library

http://www.llnl.gov/tid/Library.html 


\title{
Damage Mechanisms Of Filled Siloxanes For Predictive Multiscale Modeling Of Aging Behavior
}

\author{
Bryan Balazs, Robert Maxwell, Steve deTeresa, Long Dinh, Rick Gee \\ Lawrence Livermore National Laboratory \\ Livermore, CA 94550
}

\begin{abstract}
Predictions of component performance versus lifetime are often risky for complex materials in which there may be many underlying aging or degradation mechanisms. In order to develop more accurate predictive models for silica-filled siloxane components, we are studying damage mechanisms over a broad range of size domains, linked together through several modeling efforts. Atomistic and molecular dynamic modeling has elucidated the chemistry of the silica filler to polymer interaction, as this interaction plays a key role in this material's aging behavior. This modeling work has been supported by experimental data on the removal of water from the silica surface, the effect of the surrounding polymer on this desiccation, and on the subsequent change in the mechanical properties of the system. Solid State NMR efforts have characterized the evolution of the polymer and filler dynamics as the material is damaged through irradiation or desiccation. These damage signatures have been confirmed by direct measurements of changes in polymer crosslink density and filler interaction as measured by solvent swelling, and by mechanical property tests. Data from the changes at these molecular levels are simultaneously feeding the development of age-aware constitutive models for polymer behavior. In addition, the microstructure of the foam, including under load, has been determined by Computed Tomography, and this data is being introduced into Finite Element Analysis codes to allow component level models. All of these techniques are directed towards the incorporation of molecular and microstructural aging signatures into predictive models for overall component performance.
\end{abstract}

\section{INTRODUCTION}

Silica-filled polydimethylsiloxane (PDMS) composite systems are of broad appeal due to their chemical and environmental resilience and the availability of a wide range of tailorable chemical and mechanical properties [1-3]. This composite material is stable for decades against numerous stress inducing aging mechanisms: thermal and mechanical loads, and environmental, radiative, and chemical attack. These materials are, however, subject to chemical and physical degradation over long service lifetimes. In addition, synergistic effects of degradation mechanisms occurring simultaneously may occur over many length and timescales (see Figure 1). The result is that the mechanical property changes associated with multi-mechanism aging may be subtle and may not necessarily change linearly as a function of time in service.

Further, it is impractical to performance-test existing materials and/or components for their design lifetimes, and this is clearly impossible for new materials that have only been available for a fraction of a component's design lifetime; thus, predictive models are needed. Current models are typically an extrapolation of historical data with the prayer that the process is linear on a log-log plot. The aging process may be accelerated by 


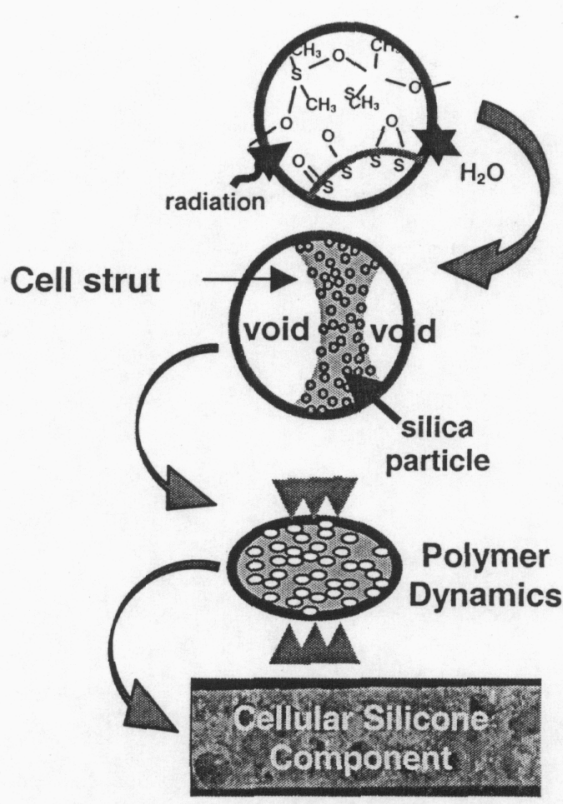

Figure 1. Diagram of the impact multiscale damage mechanisms will have on ultimate material performance issues.

increased temperature/humidity/etc, but this doesn't address the quantitative relationship of aging under the aggressive test conditions to the response at much longer times under more realistic service conditions. Rational predictive models for long term aging that acknowledge the underlying chemical and physical processes are needed. The need for these rational predictive models is particularly important for materials with significant microstructure, e.g., foams, highly filled polymers, polymer blends, and polymer composites. Because of the highly heterogeneous nature of these materials, small changes in one feature of the microstructure can often effect large overall changes in the macroscopic behavior.

Table 1. Overview of length scales and the experimental and modeling approaches applied to cellular silicon aging.

Domain

Atoms/Molecules

Polymer Viscoelasticity

Microstructure

Component
Experimental

NMR \& TPD

Crystallization\&DMA

CT

CT to Mesh
Modeling

Mol. Dynamics

Constitutive equations

n.a.

FEA

Since such linear relationships are often used in service lifetime predictions, there is a fundamental need to employ sensitive methods to investigate the structural and motional changes that occur in these materials as a result of aging in chemically, thermally, or radioactively harsh environments. Ideally, these methods would allow a complete assessment of aging mechanisms in order to yield predictive capabilities. We have developed and are testing a generalized experimental plan to address multiscale contributions to complex polymer degradation processes. These methods span from the 
atomistic to the component scale and some of the experimental approaches are listed in Table 1. This paper highlights some of our recent results.

\section{EXPERIMENTAL}

The materials studied were a copolymer of polydimethylsiloxane and polydiphenylsiloxane, crosslinked by a vinyl monomer/vinyl-specific catalyst system. The percentages of each monomer unit in the base rubber were $90.7 \mathrm{wt}$.\% PDMS, 9.0 wt.\% PDPS, and $0.31 \mathrm{wt} . \%$ polymethylvinylsiloxane. The resultant rubber was then milled with a mixture of fumed (Cab-o-sil M7-D: 21.6wt.\%) and precipitated filler (Hi-sil 233: $4.0 \mathrm{wt} . \%$ ), and $6.8 \mathrm{wt} \%$ of an ethoxy endblocked siloxane as a processing aid. The processing aid averaged about 12 monomer units long and was added to block a percentage of the surface reactive sites on the filler and to reduce the filler-polymer interaction to meet mechanical and processability property specifications. A foam composite material was then made by processing the filled polymer with prilled urea (solid spheres of urea obtained from Coastal Chem, Inc [Cheyenne, WY] with particle sizes between 0.4 and $0.7 \mathrm{~mm}$ ). The urea was subsequently washed out after curing providing a foamed composite with $\mathrm{mm}$ size pores. The investigated foams exhibited 60 percent porosity..

Details of experimental procedures for SPME, crystallization studies, NMR, solvent swelling, and molecular modeling can be found elsewhere [4,5].

\section{RESULTS AND DISCUSSION}

Laboratory aged samples subjected to $\gamma$-radiation degradation and exposure to desiccation atmospheres have been studies by NMR and molecular modeling for atomistic scale structural changes and for changes in polymer dynamics. We have previously established for M97 cellular silicones that NMR relaxation times are correlated to both polymer chain dynamics and to viscoelastic properties [5]. As such, NMR can be used to measure polymer degradation in situ. Figure 2 shows results of our NMR studies on degraded polymers. In general increased stiffening has been observed

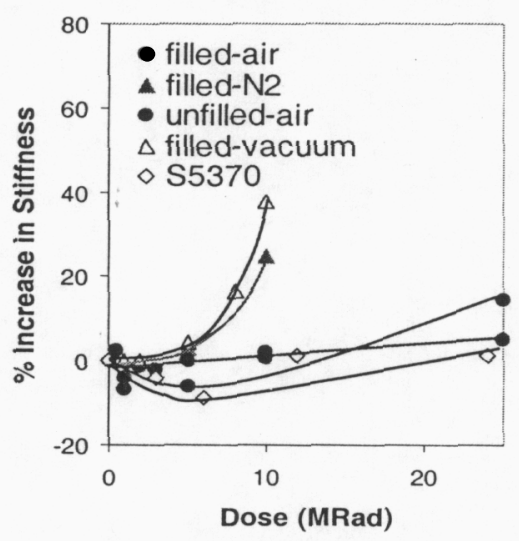

Figure 2. Increase in stiffness measured by NMR as a function of $\gamma$-radiation dose for M97. 
for all exposures, though some differences due to atmospheric conditions are detectible. Similar results have been obtained for M97 polymers aged in desiccative environments, where a significant stiffening of the polymer matrix was observed with increasing exposure time (data not shown). This has been assigned to changes in the interfacial interactions between the PDMS polymer and the inorganic filler [4]. We have modeled both degradation mechanisms with Molecular Dynamics simulations. Using this approach we have been able to validate and predict the degradation effects of ionizing radiation and changes in water speciation on the mechanical properties, as measured by the polymer dynamics, in M97 type cellular silicons.

To measure bulk changes in viscoelastic properties due to degradation mechanisms, we have also used both solvent swelling and DMA methods. Results from these studies have supported our atomistic modeling and our NMR results [6]. The results have also allowed us to span the gap between the atomistic scale and the polymer microstructure. Results from these measurements are being fed into constituitive equations to provide detailed understanding and predictive capability for the aging of these complex polymeric foams.

Inorder to observe structural changes occurring on a larger scale as a function of both physical and chemical aging, we have employed computed tomography (CT) to image pore structure collapse as a function of compression. Results from one such measurement are shown in Figure 3 and clearly image the fracture and collapse of cell walls with moderate compressions.

Predictive lifetime predictions maybe possible if data from our atomistic scale studies can be combined with our viscoelastic understanding reflected in the constitutive equations being developed with the CT data. Towards this end we have fed the CT data into Finite Element Analysis input files in combination with simple consitititive equations for the polymer viscoelastic properties [7]. The imaged polymer was then subject to simulated compression. The FEA calculation then predicted the relative strains throughout the polymer component and is shown in Figure 4. As can be seen, significant strain develops at cell wall struts. This localized strain may explain the strut collapse seen in the CT data shown in Figure 3.

\section{CONCLUSIONS}

The work reported here represents our initial efforts towards attaining a detailed understanding of the multiscale aging phenomena in cellular silicone materials aged in

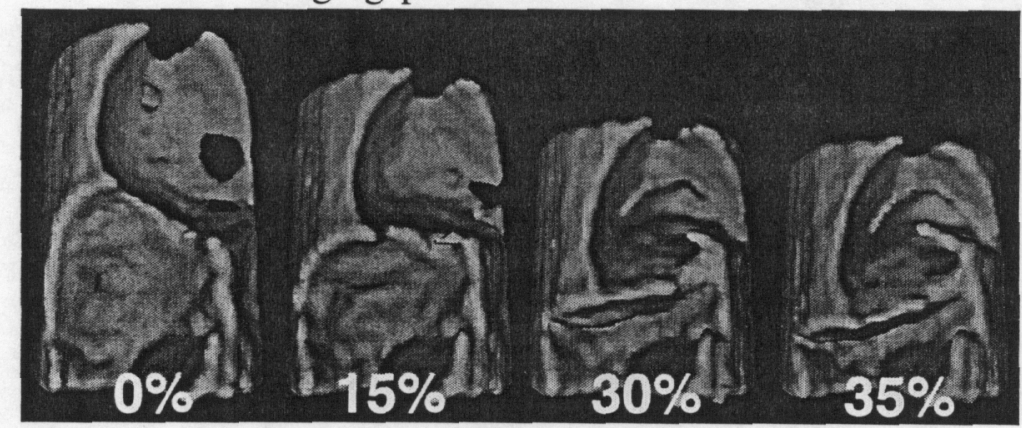

Figure 3. CT scans of pores structure deformation during compression. 


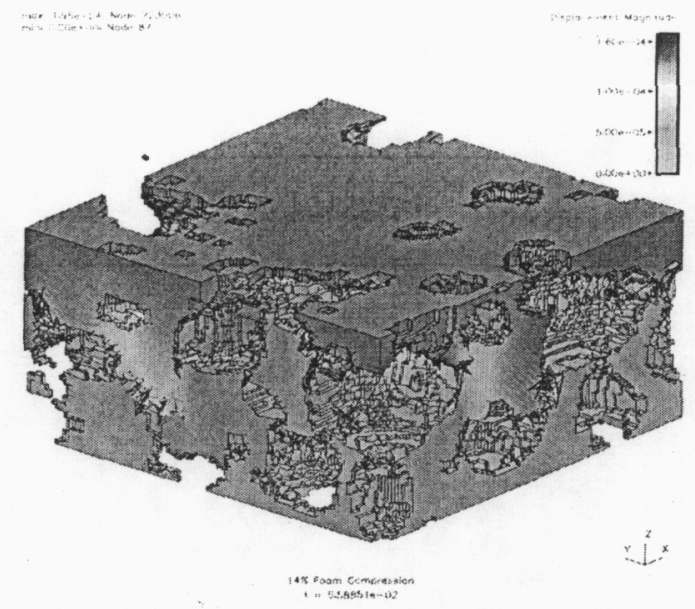

Figure 4. Results of FEA simulations of a component undergoing compression lighter areas are regions of higher strain.

radiation rich and water poor environments. We have combined experimental methods to assess aging signatures at both the atomistic and the microstructural scale with multiscale modeling approaches. Work is continuing to incorporate the chemical aging kinetics obtained from NMR, TPD, and MD calculations into constituitive equations of polymer viscoelastic response that will eventually be used in the FEA simulations.

\section{ACKNOWLEDGMENTS}

We would like to thank John Kinney and Dave Haupt for obtaining the CT images, Harry Martz and Diane Chin for converting these images into FEA accessible mesh, and Peter Raboin for running the FEA simulations. This work was performed under the auspices of the U.S. Department of Energy by the University of California, Lawrence Livermore National Laboratory, under contract \# W-7405-ENG-48.

\section{REFERENCES}

1. 'J. M. Zeigher and F. W. G. Fearon, Silicon Based Polymer Science: A Comprehensive Resource. Advances in Chemistry 224, ACS Press (1990).

2. G. Kraus, Rubber Chem. Tech., 381070 (1965)

3. P. Vondracek and A. Pouchelon, Rubber Chem. Technol., 63, 202 (1990).

4. A. Chien, R. Maxwell, D. Chambers, B. Balazs, J. LeMay, Rad. Phys. and Chem. 59, 493 (2000).

5. R. S. Maxwell and B. Balazs, J. Chem. Phys., in press (2002).

6. R. Gee, R. S. Maxwell, L. Dinh, B. Balazs, Proc. MRS Symp., in press (2002).

7. R.W. Ogden, Nonlinear Elastic Deformations, Wiley, NY, 1984. 